\title{
Hydraulic system modeling and motion control of demotion robot's working equipment
}

\author{
CEN Yu-wan ${ }^{1, a}$ \\ ${ }^{1}$ School of Mechanical Engineering \\ Anhui University of Technology \\ Maanshan, Anhui 243002, China \\ a13905550508@139.com
}

\author{
JIANG Ya-fen ${ }^{2, b}$ \\ ${ }^{2}$ School of Electrical Engineering \& \\ Information \\ Anhui University of Technology \\ Maanshan, Anhui 243002, China \\ bltahut@163.com
}

\author{
ZHANG Han-dong, \\ ${ }^{3}$ School of Electrical Engineering \& \\ Information, \\ Anhui University of Technology, \\ Maanshan, Anhui 243002, China \\ c zhanghd0406@sina.com
}

\begin{abstract}
Based on the electro-hydraulic proportional system of a demolition robot working device, a simplified mathematical model was established by analyzing dynamic characteristics of the electro-hydraulic proportional valve, flow equation, the continuity equation and force equilibrium equations, and the fuzzy self-adaptive PID controller was designed to realize position control of working equipment. The simulations reveal that, compared with traditional PID, the fuzzy self-adaptive PID controller has these advantages such as smaller overshoot, good dynamic response and steady state performance.
\end{abstract}

Keywords-demolition robot; electro-hydraulic proportional system; fuzzy self-adaptive PID; position control

\section{INTRODUCTION}

Demolition robot is a kind of multi - function remote control robot developed for high - voltage, intense radiation, high noise environment. This robot can carry out demolition works flexibility in dangerous areas and has been widely used in metallurgical, construction and cement industry. It is being greeted with increasing approval because of its reliability, security and efficiency ${ }^{[1]}$.

In order to achieve position control accurately, it is necessary to analyze the dynamic and static characteristics of the robot's hydraulic system, and establish the accurate mathematical model. But it is very difficult to set up an accurate math-model ${ }^{[2]}$, the reasons are as follows: 1) electro-hydraulic proportional system is special in fluid dynamics and electromagnetic conversion. From the control point of view, it exemplifies a high order non-linear complex system, and is influenced by the temperature and changing loads; 2) most parameters in the mathematical model are time-varying and almost related to the structure, running state and pose of the working device.

For strong nonlinear and uncertain parameter of the hydraulic system, traditional PID control can't achieve accurate position control. Although the algorithm is relatively simple, but robustness is not high, and the parameter adjustment is difficult ${ }^{[3]}$; For the more popular intelligent control, such as neural network control and fuzzy control, neural network control has fast-learned ability, but is difficult to improve the real time, the fuzzy control is suitable for nonlinear, anti-interference system, but generally exist static error, control accuracy is not high ${ }^{[4]}$. Based on the moving arm as an example, this article establish a simplified model of the hydraulic system, and fuzzy self-adaptive PID control is used for the position control, this method can adjust the parameters automatically without Precise mathematical model and achieved good control effect.

\section{THE MODEL OF ELECTRO-HYDRAULIC PROPORTIONAL POSITION CONTROL SYSTEM}

Asymmetric single lever hydraulic cylinder is the drive mechanism of the robot's working device, thus the electro-hydraulic proportional position control is the key to the realization of automatic demolition. Electro-hydraulic proportional position control system is shown in Fig.1. Through comparing the displacement signal of hydraulic cylinder piston collected by the displacement sensor with the given one, error signal is obtained. After optimization and conversion by controller, the system output controlling signal, and then the proportional amplifier amplify control signal to drive proportional valve work, finally this system achieve the hydraulic cylinder position control ${ }^{[5]}$.

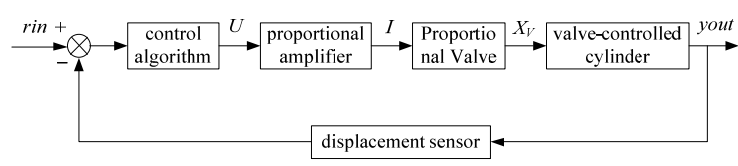

Figure 1 Electro-hydraulic proportional position control system

The proportional amplifier's corner frequency is much higher than system bandwidth, so it is regarded as a proportional element.

$$
G_{1}(s)=\frac{i(s)}{u(s)}
$$

$i(s)$-proportional amplifier output current (A); $K_{a}$-proportional coefficient; $u(s)$-proportional amplifier input voltage (V).

Proportional valve consists of proportional solenoid and control valve core; it is regarded as a second-order oscillation link. 


$$
G_{2}(s)=\frac{K_{v}}{\frac{s^{2}}{\omega_{v}}+\frac{2 \xi_{v}}{\omega_{v}} s+1}
$$

$\omega_{v}$ - natural frequency of proportional directional valve( $\mathrm{rad} / \mathrm{s}) ; \xi_{v}$-damping ratio of proportional directional valve; $K_{v^{-}}$flow gain of proportional directional $\operatorname{valve}\left(\mathrm{m}^{3} / \mathrm{s} . A\right)$.

Assume that oil pressure is 0 , pressure loss in the pipeline is neglected, pressure of the hydro-cylinder working volume is equal everywhere, bulk elastic modulus and oil temperature are constant, and due to volume of the valve cavity is small, compressibility of the valve cavity can not be considered ${ }^{[6]}$.

Flow equation of the electro-hydraulic proportional directional valve after linearization is shown below.

$$
Q_{L}=K_{q} x_{v}-K_{c} P_{L}
$$

Flow continuity equation of the asymmetric cylinder is shown below.

$$
Q_{L}=A_{P} \frac{d x_{p}}{d t}+\frac{V_{t}}{4 \beta_{e}} \frac{d P_{L}}{d t}+C_{t p} p_{L}
$$

$Q_{L}$ - load flow (L/min); $x_{v}$ - valve core displacement of multiple directional valve $(\mathrm{m}) ; p_{L}$ - pressure drop of load(Mpa); $K_{q^{-}}$flow gain of valve $\left(\mathrm{m}^{3} / \mathrm{s} \mathrm{A}\right) ; K_{c}$-pressureflux coefficient(m3/spa); $A_{P}=A_{1}$ - effective area of the hydraulic cylinder piston $\operatorname{rod}\left(\mathrm{m}^{2}\right) ; x_{p}-$ piston displacement $(\mathrm{m}) ; V_{t}$ - total volume of the hydraulic cylinder control cavity $\left(\mathrm{m}^{3}\right) ; \beta_{e}$ - bulk modulus of the oil $\left(\mathrm{N} / \mathrm{m}^{3}\right)$; $C_{t p}$ - total leakage coefficient of hydraulic cylinder $\left(\mathrm{m}^{3} \cdot \mathrm{Mpa} / \mathrm{s}\right)$.

Ignoring oil quality and the nonlinear load such as coulomb friction, supposing load quality to be $M$ and reverse load to be $F_{L}$, the equation of the hydraulic cylinder output power and load balance is shown below.

$$
\begin{aligned}
A_{1} P_{1}-A_{2} P_{2} & =A_{p} p_{L} \\
& =M \ddot{x}_{p}+B_{p} \dot{x}_{p}+K x_{p}+F_{L}
\end{aligned}
$$

$M$-total quality of piston and load $(\mathrm{kg}) ; B_{p}$-viscous damping coefficient of piston( $\mathrm{N} \cdot \mathrm{s} / \mathrm{m}) ; x_{p^{-}}$displacement of hydraulic cylinder piston rod $(\mathrm{m}) ; K$-elastic modulus of $\operatorname{load}(\mathrm{N} / \mathrm{m})$.

Due to the demolition robot hydraulic cylinder is inertia load, elastic modulus of the load elastic modulus $\mathrm{K}$ is 0 ; also, total leakage coefficient of Hydraulic cylinder and viscous damping coefficient of Piston can be ignored because they have small order of magnitude. Assuming $F_{\mathrm{L}}$ is 0 . Then, the solutions for Eq.3, Eq.4, Eq.5are obtained by using Laplace transformation, with which a valve controlled non-symmetry hydraulic cylinder model is also built.

$$
G_{3}(s)=\frac{X_{p}(s)}{X_{v}(s)}=\frac{K_{q} / A_{1}}{s\left(\frac{s^{2}}{\omega_{h}^{2}}+\frac{2 \xi_{h}}{\omega_{h}} s+1\right)}
$$

Natural frequency of Hydraulic cylinder load system $\omega_{h}=\sqrt{\frac{4 \beta_{e} A_{1}^{2}}{M V_{t}}}$; damping ratio of hydraulic cylinder load system $\xi_{h}=\frac{K_{c}}{A_{1}} \sqrt{\frac{M \beta_{e}}{V_{t}}}$.

Transfer function of the displacement sensor is shown below.

$$
G_{4}(s)=K_{m}
$$

According to Eq.1, Eq.2, Eq.6 and Eq.7, transfer function for working device hydraulic system is shown below.

$$
G(s)=G_{1}(s) G_{2}(s) G_{3}(s) G_{4}(S)
$$

\section{FUZZY SELF-ADAPTIVE PID CONTROLLER DESIGN}

Considering the nonlinear characteristics of the system, and ensuring system has good stability and robustness when parameters change and the load disturbance, the fuzzy self-adaptive PID controller is designed to optimize the PID parameters in real time ${ }^{[7]}$.

The relationship of the traditional PID input $e(t)$ and output $u(t)$ is shown below.

$$
u(t)=k_{p}\left[e(t)+\frac{1}{T_{i}} \int e(t) d t+T_{d} \frac{d e(t)}{d t}\right]
$$

The key of PID control is the three parameters' tuning, but the traditional setting method is not adaptive. In this paper, the parameters are set automatically by fuzzy PID control.

The fuzzy self-adaptive PID controller uses the error $e$ and the error rate $e_{c}$ as input, and according to the fuzzy control rules ${ }^{[8]}$, the PID parameters online modification is processed. 


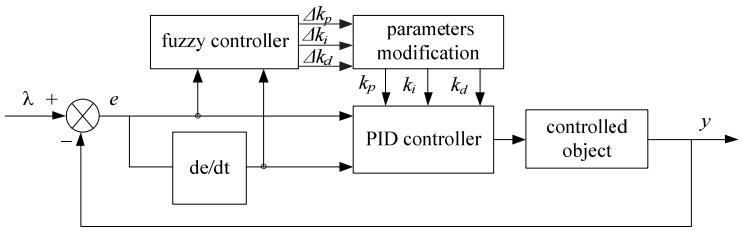

Figure 2 Step signal output response comparison

Function of the three parameters in different moments and relationship among them must be taken into account when PID parameters are set. According to the influence on system output response of $k_{\mathrm{p}}, k_{\mathrm{i}}, k_{\mathrm{d}}$ and the accumulation of practical experience, when in different $e$ and $e_{c}$, fuzzy control rules of $\Delta k_{\mathrm{p}}, \Delta k_{\mathrm{i}}, \Delta k_{\mathrm{d}}$ are as shown below ${ }^{[9,10]}$.

(1) when the error $|e|$ is relatively large, in order to make the system has a good tracking performance, no matter how the change tendency of the error is, lager $\Delta k_{\mathrm{p}}$ and smaller $\Delta k_{\mathrm{d}}$ should be taken. At the same time, to avoid system response appear larger overshoot, small $\Delta k_{\mathrm{i}}$ be taken to limit

Table 1 fuzzy rules of $\Delta k_{\mathrm{p}} \quad \Delta k_{\mathrm{i}} \quad \Delta k_{\mathrm{d}}$

\begin{tabular}{|c|c|c|c|c|c|c|c|}
\hline & NB & NM & NS & $\mathrm{ZO}$ & PS & PM & PB \\
\hline NB & $\mathrm{PB} / \mathrm{NB} / \mathrm{F}$ & $3 / \mathrm{NB}$ & $\mathrm{M} / \mathrm{NM} / \mathrm{NB}$ & $\overline{\mathrm{M} / \mathrm{NI}}$ & $\overline{\mathrm{S} / \mathrm{NS}}$ & $\mathrm{ZO} / \mathrm{ZC}$ & $\mathrm{ZO} / \mathrm{Z}$ \\
\hline NM & $\mathrm{PB} / \mathrm{NB} / \mathrm{PS}$ & $\mathrm{PB} / \mathrm{NB} / \mathrm{NS}$ & $\mathrm{PM} / \mathrm{NM} / \mathrm{NB}$ & $\mathrm{PS} / \mathrm{NS} /$ & $\mathrm{PS} / \mathrm{NS} /$ & $\mathrm{ZO} / \mathrm{ZC}$ & $\mathrm{NS} / \mathrm{ZO} / \mathrm{ZO}$ \\
\hline NS & $\mathrm{PM} / \mathrm{NB} / \mathrm{ZO}$ & $\mathrm{PM} / \mathrm{NM} / \mathrm{NS}$ & $\mathrm{PM} / \mathrm{NS} / \mathrm{NM}$ & $\mathrm{PS} / \mathrm{NS} / \mathrm{NM}$ & $\mathrm{ZO} / \mathrm{ZO} / \mathrm{NS}$ & NS/PS/NS & NS/PS/ZO \\
\hline $\mathrm{ZO}$ & $\mathrm{PM} / \mathrm{NM} / \mathrm{ZO}$ & $\mathrm{PM} / \mathrm{NM} / \mathrm{NS}$ & $\mathrm{PS} / \mathrm{NS} / \mathrm{NS}$ & $\mathrm{ZO} / \mathrm{ZO} / \mathrm{NS}$ & NS/PS/NS & $\mathrm{NM} / \mathrm{PM} / \mathrm{NS}$ & $\mathrm{NM} / \mathrm{PM} / \mathrm{ZO}$ \\
\hline PS & $\mathrm{PS} / \mathrm{NM} / \mathrm{ZO}$ & $\mathrm{PS} / \mathrm{NS} / \mathrm{ZO}$ & $\mathrm{ZO} / \mathrm{ZO} / \mathrm{ZO}$ & $\mathrm{NS} / \mathrm{PS} / \mathrm{ZO}$ & $\mathrm{NS} / \mathrm{PS} / \mathrm{ZO}$ & $\mathrm{NM} / \mathrm{PM} / \mathrm{ZO}$ & $\mathrm{NM} / \mathrm{PB} / \mathrm{ZO}$ \\
\hline PM & $\mathrm{PS} / \mathrm{ZO} / \mathrm{PB}$ & $\mathrm{ZO} / \mathrm{ZO} / \mathrm{PS}$ & NS/PS/PS & NM/PS/PS & NM/PM/PS & $\mathrm{NM} / \mathrm{PB} / \mathrm{PS}$ & $\mathrm{NB} / \mathrm{PB} / \mathrm{PB}$ \\
\hline PB & $\mathrm{ZO} / \mathrm{ZO} / \mathrm{PB}$ & $\mathrm{ZO} / \mathrm{ZO} / \mathrm{PM}$ & NM/PS/PM & $\mathrm{NM} / \mathrm{PM} / \mathrm{PM}$ & NM/PM/PS & $\mathrm{NB} / \mathrm{NB} / \mathrm{PS}$ & $\mathrm{NB} / \mathrm{PB} / \mathrm{PB}$ \\
\hline
\end{tabular}

The Mamdani minimum-maximum inference has a large allowance on choice of membership function. Although it will be likely to lose some useful information, the defuzzification process has bigger influence on control than the fuzzy inference synthesis. In this paper, we use Mamdani minimum-maximum inference method to synthesize. The form of the fuzzy inference is shown below.

\section{$R$ : If $x$ is $A$ and $y$ is $B$ then $Z$ is $C$}

The method of weighted mean is used in the defuzzification, and it is suitable for that the output fuzzy sets membership function is symmetrical. If the domain of $U$ is discrete, $U=\left\{u_{1}, u_{2} \ldots u n\right\}$, the membership function of $u_{j}$ is $A\left(u_{j}\right)$, and the calculation formula as shown below. integral action.

(2) when the error $|e|$ is medium, in order to make the system response has small overshoot, smaller $\Delta k_{\mathrm{p}}$ should be taken, ensuring that the response speed of system appropriate, $\Delta k_{\mathrm{i}}$ and $\Delta k_{\mathrm{d}}$ should be moderate. Especially the value of $\Delta k_{\mathrm{d}}$ affect system response.

(3) when the error $|e|$ is relatively small, to ensure that the system has good steady-state performance, $\Delta k_{\mathrm{p}}$ and $\Delta k_{\mathrm{i}}$ should be taken larger. To avoid system oscillate near the set point, and considering anti-interference of the system, larger $\Delta k_{\mathrm{d}}$ is chosen when $|e c|$ is small and vice versa.

Without loss of generality, the domain of the controller input variable $e, e c$ and output variable $\Delta k_{\mathrm{p}}, \Delta k_{\mathrm{i}}, \Delta k_{\mathrm{d}}$ are [-3, $3]$, and seven language value $\{\mathrm{NB}, \mathrm{NM}, \mathrm{NS}, \mathrm{ZO}, \mathrm{PS}$, $\mathrm{PM}, \mathrm{PB}\}$ are used to describe them. NB, PB are taken for $\mathrm{S}$ membership function, and he others are taken for triangle membership function.

Fuzzy control rules of $\Delta k_{\mathrm{p}}, \Delta k_{\mathrm{i}}, \Delta k_{\mathrm{d}}$ is shown in table 1.

Table 2 Hydraulic system technical parameters

\begin{tabular}{|c|c|c|c|c|c|c|c|}
\hline$K_{\mathrm{a}}$ & $K_{\mathrm{v}}$ & $K_{\mathrm{m}}$ & $K_{\mathrm{q}}$ & $\omega_{\mathrm{v}}(\mathrm{rad} / \mathrm{s})$ & $\omega_{\mathrm{h}}(\mathrm{rad} / \mathrm{s})$ & $\zeta_{\mathrm{v}}$ & $\zeta_{\mathrm{h}}$ \\
\hline 1 & 1 & 1 & $1.11 \times 10^{-3}$ & 62.8 & 63.96 & 0.72 & 0.25 \\
\hline
\end{tabular}

Substituting the parameter into electro-hydraulic proportional system model, we can get the simulation results of PID and fuzzy self-adaptive PID, as shown 
below.

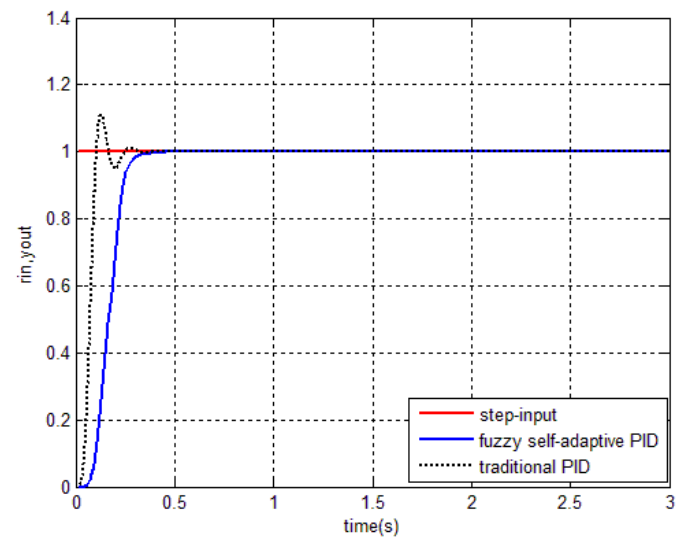

Figure 3 Step signal output response comparison

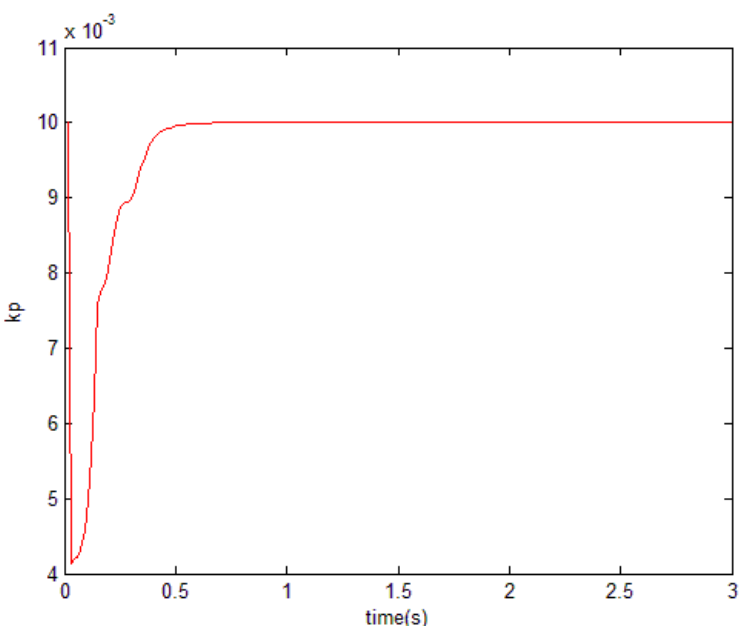

Figure 4 Adaptive adjustment of ki

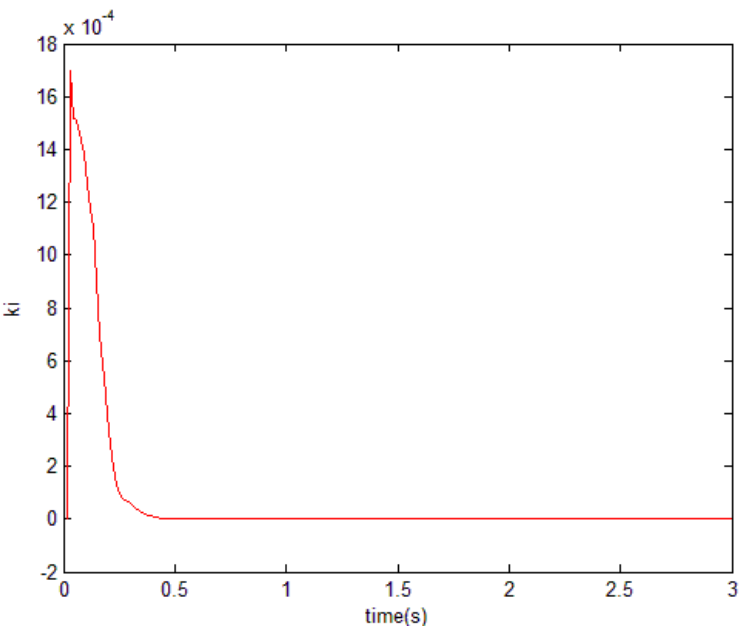

Figure 5Adaptive adjustment of ki

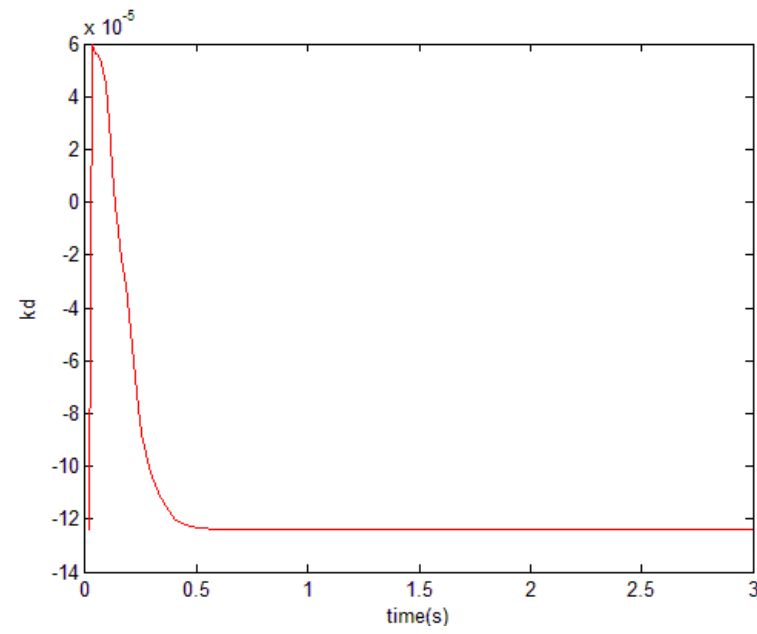

Figure 5 Adaptive adjustment of kd

Comparing analysis of the simulation curve of traditional PID and fuzzy self-adaptive PID, we can draw the following conclusions:

(1) In the step response curve of traditional PID controller, the system overshoot is $7.59 \%$ but zero in the fuzzy self-adaptive PID controller, which reduce the hydraulic system pressure peak and the impact of the power source.

(2) In Figure.3, the traditional PID control system oscillation phenomenon is obvious until the output stably. But the fuzzy self-adaptive PID control process is relatively stable, which improve the stability of the system and reduce the hydraulic system pressure fluctuation and the load of whole machine.

(3) The traditional PID controller achieved steady state in $0.43 \mathrm{~s}$. But the fuzzy self-adaptive PID controller' speed up the system response time to $0.39 \mathrm{~s}$.

(4) The simulation result shows that the fuzzy self-adaptive PID control is better than traditional PID control and can reduce the static error from $2.22 \times 10^{-4}$ to $5.22 \times 10^{-15}$, which has more stable control effect to solve the low control precision of fuzzy control.

\section{V.CONCLUSIONS}

According to the characteristics of demolition robot working device's electro-hydraulic proportional system, such as strong nonlinear, time-varying, and Modeling difficultly, in this paper, a fuzzy self-adaptive PID controller is designed, it has both the advantage of fast response and strong adaptability fuzzy control has and the advantage of high steady precision PID control has. The simulation results proved that, compared with the traditional PID, the fuzzy self-adaptive PID controller has the characteristic of quicker response, no overshoot and higher steady accuracy. The dynamic and static performance of the system are obvious improvement, finally realized the demolition robot position accuracy control. 


\section{REFERENCES}

[1] SONG Shupin, QIAN Guozhong, LUO Ming. Parameter modeling of GTC - 650 demolition robot working device, J. Engineering Machinery, 2008, 39(5): pp.35-39.

[2] TAN Xiangmin, ZHAO Dongbin, YI Jianqiang, et al. Motion control of Omni-directional mobile manipulator I - model and control ,J. Chinese Journal of Mechanical Engineering, 2009, 45(1): pp.35-41.

[3] NI Jing, XIANG Zhanqin, PAN Xiaozhong. Rough-Fuzzy PID control and ITS application to auto-shaping machine, J. Journal of Mechanical Engineering, 2006, 42(10): pp.224-228.

[4] $\mathrm{Gu} \mathrm{J}, \mathrm{Ma} \mathrm{XD}, \mathrm{Li} \mathrm{JF}$. Linear and nonlinear control of a robotic excavator, J. Journal of Central South University, 2012, 19(7): pp.1823-1831.

[5] XU Yiming. Electro-hydraulic proportional control system analysis and design. China Machine Press, Beijing, 2005.

[6] YANG Junhong, YIN Ziqiang, LI Shengyi. Nonlinear modeling and feedback linearization of valve-controlled asymmetrical cylinder, J. Journal of Mechanical Engineering, 2006, 42(5): pp.204 207.

[7] ZHANG Defeng. MATLAB fuzzy system design. National Defense Industry Press, Beijing, 2009.

[8] ZHOU Liying, ZHAO Guoshu. Application of fuzzy-PID control algorithm in uniform velocity temperature control system of resistance furnace, J. Chinese Journal of Scientific Instrument, 2008, 29(2): pp.405-409.

[9] Dinh Quang Truong, Ahn, Kyoung Kwan. Parallel control for electro hydraulic load simulator using online self tuning fuzzy PID technique, J. Asian Journal of Control, 2011, 13(4): pp. 522-541

[10] FANG Huaiying, YANG Jianhong, WU Shiping. Hydraulic leveling system for asphalt mortar vehicle based on fuzzy PID contro strategy. Journal of Chang'an University (Natural Science Edition), 2011, 31(1): pp.98-101. 